\title{
Language Acquisition During and After Critical Period (A Comparative Review Between Children and Adults)
}

\author{
Muteb Ali Alzahrani \\ College of Sciences and Arts, Muhayil Asir \\ King Khalid University, Kingdom of Saudi Arabia \\ Abha, Saudi Arabia \\ E-mail:mareb@kku.edu.sa
}

Received: September 19, 2020 Accepted: October 30, 2020 Published: November 17, 2020

doi:10.5296/ijl.v12i6.17948

URL: https://doi.org/10.5296/ijl.v12i6.17948

\begin{abstract}
This research paper is a review of the previous literature that focuses on whether or not there is an influence of second language acquisition during 'critical period'. Critical period refers to acquiring a second language before the age of adulthood. Although there is no consensus among linguists on the impact of the critical period, numerous scholars in the field of second language acquisition agree that language learners gain more benefits during the critical period including mastering the phonological system of the target language. In addition, this paper compares between the potential linguistic benefits between young learners who acquire language at an early age of their lives and their older counterparts who begin learning a language after the age of maturation. Interestingly, those who start studying a second language during the critical period usually outperform their older counterparts due to their exceptional memory traits and fresh speech organs ultimately, it displays the appropriate teaching approaches based on age benefiting from the idea of critical period hypothesis.
\end{abstract}

Keywords: Second language acquisition, Language learning, Children, Adults, Critical period

\section{Introduction}

Many researchers have devoted papers to studying the critical period hypothesis $(\mathrm{CPH})$ of second language (L2) acquisition. This paper discusses main issues related to the definition of the $\mathrm{CP}$ among researchers and looks at the differences between investigators of the $\mathrm{CPH}$ on the commencement and culmination of the CP. It is believed that the CP is a limited period in 
which children have a good level of capability to acquire an L2 more easily than post-pubertal learners (Moskovsky 2001). This essay also looks at the differences between children and post-pubertal learners on L2 acquisition; for example, children L2 learners often have higher accuracy in pronunciation over their adult counterparts (Flege, 1988). Further, it examines the similarities between children and adults in L2 acquisition, such as first language (L1) transfer and motivation. The ultimate aim of this paper is to examine how teachers can take advantage of $\mathrm{CPH}$ approaches and apply them to their teaching practices.

This paper focuses briefly on opponents' arguments of the CP and proponents' evidence of the existence of the CP. It also examines whether there is a consensus among researchers about the definition of the $\mathrm{CP}$, and the onset and offset of the CP. Additionally, this paper pays particular attention to the linguistic abilities that children have, and adults' linguistic abilities that they possess and how these abilities can be employed to achieve sophisticated ways of L2 learning.

This essay observes and analyses several teaching approaches with L2 children and adults, benefiting from the $\mathrm{CPH}$. These methods include, input and output, Implicit and explicit teaching. In addition, Feedback, motivation, and L2 learners' personalities. Thus, both L2 children and adults have different and similar ways on SLA. This essay demonstrates significant teaching approaches that would serve L2 teachers to be aware of the age of L2 learners (children or adults) in order to employ the appropriate teaching methods for the targeted learners (Munoz, 2008).

\section{The Definition of the CP Among Researchers and Possible Reasons Beyond the Different Success Between L2 and Adults}

$\mathrm{CPH}$ researches do not propose a single definition of the CP. However, most have agreed that learning an L2 during the CP is better than learning after maturation. Moskovsky (2001) suggested that the $\mathrm{CP}$ in $\mathrm{L} 2$ acquisition refers to a limited period during the early years of life when people are able to exercise a certain capability of language learning; that is, linguistic abilities must be exercised during this period lest they die out. Singleton (2005) stated that the $\mathrm{CP}$ can be defined 'as being of limited duration within well-defined and predictable termini and as being related to very specific capacities or behaviors' (p.270). Further, Moskovsky (2001) cited cases of people who achieved a very high proficiency in L2 acquisition after language learning during the $\mathrm{CP}$; however, the $\mathrm{CPH}$ in L2 acquisition is concerned with the unlikelihood of success obtained by children and adults when learning an L2 (Bialystok \& Hakuta, 1999). Lenneberg (1967) proposed the idea of an intrinsic instrument that may be in charge of changes in linguistic abilities when reaching puberty, i.e., a neurological process. The idea is that this neurological change would retard certain L2 learning abilities after maturation. Further, Singleton (2001) suggested that the efficiency of the CP through the plasticity in children's brains, indicating children's ability to learn an L2 more quickly.

Moreover, Scovel (2000) stated that infants are linguistically precocious to developmental neurology; that is, younger children improve their capabilities very quickly relative to language learning. This is underpinned by Lamendella (1977), who suggested that the immature neurolinguistic system makes L2 learning easier for children. This allegation was 
reinforced by Long (1990), who suggests that learning in the CP can control the level of language development. During the $\mathrm{CP}$, acquiring linguistic capabilities, e.g., pronunciation mastery is more likely to be successful. After this period, language acquisition is seen as being more difficult, and learners are more limited in achieving proficiency. In addition, the influence on L2 acquisition after the CP is not confined to the phonological system, and this could affect other linguistic aspects, such as L2 grammatical acquisition. Many papers have attributed the linguistic precocity of infants to neurological developments (Spinney, 1999; Scovel, 2000). So, it has been demonstrated that there is a $\mathrm{CPH}$, but there is no consensus among researchers about a single definition or description of the $\mathrm{CP}$.

\section{The Beginning and the End of the CP}

As previously mentioned, there is no consensus on one definition of the $\mathrm{CP}$, nor is there a consensus on the beginning and end of the $\mathrm{CP}$. The $\mathrm{CPH}$ suggests the importance of the age at which learners commence acquiring an L1 or L2 (Bialystok \& Hakuta, 1999). Lenneberg (1967) proposed that the CP extends 'from early infancy until puberty'. Johnson and Newport (1991) explained that L2 research asserts that language learning abilities reach their peak at two years of age, the older the individual, the less linguistic abilities they may achieve until puberty is complete. Flege (1988) argued that the CP is over before the age of twelve, especially for speech learning. Nevertheless, Lenneberg (1967) proposed that the CP extends 'from early infancy until puberty'. This is in line with the ideas of Hurford (1991), who suggested that the CP ends around maturation. Singleton (2001) also proposed that nine years of age is the age at which the CP reaches its ultimate point; after this age, learning an L2 may be more difficult. However, Long (1990) explained that the CP starts at six years of age and can occur up until adolescence. Consequently, $\mathrm{CPH}$ investigators have come up with different suggestions about the onset and offset of the $\mathrm{CP}$, however, most of them are in agreement that the $\mathrm{CP}$ starts at an early age up until puberty.

\section{Opponents of the CP and Proponents' Evidence of the Existence of the CP}

However, there are opponents of the CPH. Ellis (2013) stated that the philosophy of 'the younger, the better' may not always be true; rather, it might be only partially true. Opponents believe that it is not the $\mathrm{CP}$ that assists learners to acquire an L2 so much as it is the development of language over a longer period. So, this period could be a natural process and the linguistic ability would decay over time. Moreover, certain researchers such as Ellis and Shintani (2014) have stated there is not enough of a chance to acquire an L2 fully in the CP. Rather, the capability of acquiring L2 witnesses decay over time beginning from an early age. In addition, Deng and Zhu (2016) offered studies that explain that acquiring a foreign language might only begin at the age of 12, which may allow older language learners to achieve native speaking proficiency on the condition that their teachers use good teaching methods and provide an advantageous language environment. Therefore, confirming the existence of the advantages of the $\mathrm{CP}$ requires more evidence.

Proponents of the $\mathrm{CPH}$ have presented some evidence of $\mathrm{CP}$ existence. Geny, who had been in a room for 20 months of age, did not talk. From 20 months until 13 years of age, she did not speak. If she made a noise, she would be beaten by her father. After she was recovered, 
she began acquiring language skills. However, Geny had deficiencies in both the comprehension and production of language; that is, she could not reach native proficiency. Because she did not use the left hemisphere of her brain for language acquisition in the very early stages of her life, she lost native capabilities of language acquisition. Geny's case may prove the CPH (Hoff, 2014).

\section{Differences Between L2 Children and L2 Adults in Second Language Acquisition}

In fact, L2 children and adults are different in many aspects on SLA, and they possess different abilities to learn SL. Scovel (2000) suggested that the CPH contrasts children and adults, and several studies have followed the perception of 'the younger, the better'. Adults and children use different mechanisms to learn, and they perceive language differently; for example, children do not need to imitate linguistic structures to learn, but many post-pubertal learners require conscious reflection (DeKeyser, 2005). Krashen et al. (1979) proposed that, at the beginning of L2 acquisition, older children and post-pubertal learners learn more quickly than younger children, whereas younger children are better learners in the long term. This is in line with the ideas of Muñoz (2006), who stated that older L2 learners are more successful in the first stages of language learning, whereas L2 children are better learners in ultimate L2 acquisition. Moreover, older L2 learners surpass L2 children in explicit learning, while children are better learners in implicit learning. Implicit learning refers to language acquisition taking place unconsciously through a great deal of linguistic input (input refers to what learners hear and read which represented by listening and reading skills), whereas explicit learning refers to conscious and intentional language acquisition by asking and discussing through output (output refers to learners' production of language, namely speaking and writing) noticing and analysing linguistic aspects (Shanks, 2005, Ellis, 2006, Long, 1996).

Pronunciation is often acquired differently between L2 children and adults. Flege (1988) expressed the belief that the $\mathrm{CP}$ has a significant influence on pronunciation skills. Children learning an L2 in the CP may become as proficient as native speakers. A study on L2 pronunciation in children and adults considered the period spent in an English-speaking country (the US) where the adults had lived for five years and the children had lived for one year. In time, it was found that the children surpassed the adults in terms of pronunciation accuracy, as they were very close to native English pronunciation. Hence, the length and experience of language learning was not advantageous for adults, and though the period was shorter, rapid learning was more effective for children than for their adult counterparts. However, Agulló (2006) stated that younger people are not necessarily faster learners or better in all linguistic aspects; for example, adults can outperform children in grammar, whereas children surpass their adult counterparts in pronunciation. So, there is a difference between L2 children and post-pubertal learners in SL pronunciation accuracy.

Other researchers illustrated more linguistic differences between L2 children and adults. Lenneberg (1967) referred to a study of 46 Chinese and Korean speakers between the ages of 3 and 29 who lived in the US. These individuals were widely tested in areas such as English grammar variety and grammatical judgement use. According to the study, particular 
differences in linguistic abilities exist; the earlier arrivals to the US performed better in the linguistic tests than the later arrivals until the age of adolescence. Johnson and Newport (1989) found a relationship between the learning age and the eventual performance of learners in the grammatical aspects of an L2, proving that children have an advantage over post-pubertal learners. They tested a large group of learners across different age groups, all of whom had previously been living in the US. Some began to learn English as an L2 before seven years of age, and the rest began learning after. The participants who lived in the US before seven years of age achieved native English performance; however, subjects who arrived in the US after were found to have a linear decrease in proficiency and performance until maturation.

Learning methods and linguistic abilities could be divers between L2 children and adults. Adults tend to perform better when provided with formal instructions. In other words, adults acquire language skills more effectively when they are taught explicitly. Once adults have the ability to analyse linguistically, they are more aware of metalinguistic aspects (metalinguistic is knowledge that deals with attributes of language such as semantics, syntax, and morphology). However, children are better learners when they are taught implicitly, which is how children often acquire language; that is, they absorb language unconsciously, indicating to the memory traits of (DeKeyser, 2005;Ellis, 2009; Krashen, 1982; Agulló, 2006).

\section{Similarities Between L2 Children and Adults in Second Language Acquisition}

Studies have illustrated the similarities between children and adult L2 learners, such as the influence of language transfer from the L1 to the L2. Rocca (2007), focusing on former studies, argued that children L2 learners and post-pubertal learners both tended to transfer from their L1 into the target language, for example, transferring the tense-aspect system of the L1. In addition, Craats (2001) designed a study that included L2 children and adult learners whose native language was Turkish and the target language Dutch. The results of this study showed an obviation from the L2 possessive pronoun system due to influences from the learners' L1. Therefore, both children and adult L2 learners share L1 transfer traits. There is another similarity between older children (during the CP) and adults when they acquire L2. Gelkerson (2004) illustrated this in a study of 11 children and 11 adult L2 English learners whose native language was Spanish. The children were first exposed to English at the age of five, and the adults began learning English at the age of 18. The researcher observed how the subjects produced certain particle verbs. The results of this study referred to particular similarities in the usage of particle verbs by children and adult L2 learners.

The other similar factor between L2 children and adults in SLA is motivation. It has a deep influence on L2 children and post-pubertal learners. Ellis (1997) defined motivation as 'the attitudes and affective states that influence the degree of effort that learners make to learn an L2' (p.75). Lai (2011) suggested two types of motivation: intrinsic and extrinsic, stating, 'Intrinsic motivation is animated by personal enjoyment, interest, or pleasure, whereas extrinsic motivation is governed by reinforcement contingencies' (p.2). Further, Staci-Anne (2013) stated that L2 learners (both children and adults) need to be motivated, as motivation 
is very important in language learning. This is why Gass and Selinker (2001) proposed that motivation could be a predictor of success in L2 learning. Motivation is a personality factor; other personality factors might be exemplified by traits like 'introverted' or 'extroverted', for example, and these factors affect L2 acquisition in one form or another. For example, having an extroverted personality is seen to assist L2 acquisition, as learners are motivated to achieve certain goals of learning. However, an introverted personality could retard the active learning of an L2 if a learner is unwilling to practice what he or she has taught (Staci-Anne, 2013).

The other similarity between L2 children and post-pubertal learners is their need for feedback. Petchprasert (2012) suggested that feedback in language learning is perceived to contribute largely to L2 learners' achievements, including the consequences of their performance. Learners would benefit from the feedback given by their teachers by finding and fixing their mistakes. If an L2 learner has not made mistakes, they can still benefit from further encouragement and can become more motivated to proceed with the L2 learning process. Therefore, both L2 children and adults face similar difficulties in L2 learning such as L1 transfer. However, they are in need of motivation to make progress in L2 in addition to their need to be given feedback in order to be aware of their errors.

\section{Teaching Approaches Benefiting From the CPH; Input and Output in L2 Children and Adults' Teaching}

From the aforementioned studies comparing children L2 learners to their adult counterparts, it is clear that a set of factors need to be considered by teachers to apply them when teaching an L2. First, both children and post-pubertal L2 learners should be exposed to large quantities of the L2, especially children since they have salient memorisation qualities and are more likely to utilize strategies similar to native-like processing (Munoz, 2008). In other words, children L2 learners need a greater focus on input than output. Since they are not fully aware of metalinguistic aspects. For example, when a child learning English is asked to explain how the present perfect is used, he/she might not be able to answer such a question but still be capable of using this language function very well. This could be attributed to unconscious learning. Therefore, it is good to increase reading and listening materials that represent input, for instance teachers write comprehension questions on the board related to film and then let L2 children watch the film without subtitles. Also, during teaching sessions, L2 adults watch films (with subtitles in their L1, if they are beginners) and the teacher urges them to notice characters' personalities and describe them by giving the students a list of adjectives beforehand (Krashen, 1982; Long, 1996; Shanks, 2005, Agulló, 2006). Accordingly, intensive L2 exposure is important to learning and helps to restrict L1 transfer by adapting L2 input comprehension.

After teachers intensify input to L2 learners through listening and reading tasks, output should be activated by giving learners opportunities to participate by producing what they have learned (especially L2 adults). Output is very important in developing an L2.This can be done through assigning speaking and writing tasks. In addition, techniques to accomplish this task include placing students in groups that blend high and low-level learners (so they can 
correct each other's mistakes), having students exchange papers during writing tasks and instructors asking each group to participate. By such approaches, L2 learners would be activated, which would benefit L2 learning as learners interact in the L2 (Munoz, 2008).

\section{Implicit and Explicit Teaching on L2 Children and Adults}

Implicit and explicit methods of teaching must be taken into consideration when teaching an L2. It is believed that implicit teaching could be more effective for children than adults. As shown in several studies (e.g. Shanks, 2005), when L2 children are taught implicitly, they are expected to be good long-term learners. Further, implicit teaching is more successful for children because they tend to acquire language skills subconsciously rather than consciously. Consequently, when students are exposed to a great deal of implicit teaching, it often results in more L2 knowledge and natural learning (Ellis \& Shintani, 2014). Therefore, teachers should aim to teach L2 children implicitly since children tend to absorb L2 faster owing to certain characteristics, such as good memorisation skills (DeKeyser, 2005; Krashen, 1982; Agulló, 2006). In addition, teachers need to devote more time to teaching L2 children listening skills; several studies have shown L2 children's higher capabilities in the phonological system than their adult counterparts, meaning children could reach native levels of the L2 during the CP (Flege, 1988).

In contrast, post-pubertal learners appear to learn a language consciously (Krashan, 1982). Accordingly, explicit teaching could be better for adults to make progress in language learning since they usually possess greater analytical abilities than children, such as an awareness of metalinguistic aspects like the qualities of or reasons behind certain structures of an L2. In addition, an explicit teaching approach should be highlighted when teaching adults and giving them the formal instructions of learning a language. Since adults possess reasoning skills like the ability to reflect and analyse, so they are granted the ability to learn grammatical features of an L2 more clearly than children are able to (Ellis \& Shintani, 2014; Agulló, 2006).

The $\mathrm{CPH}$, as the aforementioned studies demonstrate, shows that children may need special teaching methods due to how they mentally and physically develop. For instance, teachers describe particular pictures (pictures of animals), practicing speaking and listening to accurate and fluent pronunciation (such as songs in L2) is all beneficial for L2 children (Deng $\&$ Zhu, 2016). Accordingly, Ellis (2009) suggested that implicit learning is usually featured in L2 teaching in the way that children absorb information and acquire information for the long term. However, this type of learning may require good memorisation skills. Explicit learning is also featured in certain skills, such as analytical abilities and the reasoning of adult L2 learners, allowing them to verbalise what they have learnt.

\section{The Significance of the Study}

This research paper is important mainly for teachers. Initially, it connects theoretical features of $\mathrm{CPH}$ with educational practices. For instance, it raises languages instructors' awareness towards certain linguistic issues including choosing the appropriate teaching approaches based on the ages of learners. For example, teachers should teach L2 children implicitly since 
they possess exceptional mental capabilities during childhood such as memorizing linguistic items easily and mastering L2 pronunciation. However, according to $\mathrm{CPH}$, L2 adults need to be taught explicitly as they have analytical and reasoning skills. This allows them to raise questions to their instructors to understand syntactic rules.

\section{Conclusion}

A large number of studies support the existence of the $\mathrm{CPH}$, but researchers such as Ellis (2014) disagree with the CPH, stating that the CP does not affect L2 acquisition as much as the $\mathrm{CPH}$ proposes. Although proponents of the $\mathrm{CPH}$ demonstrate the case of Geny as explicit evidence for the CPH, L2 adults may be better in certain aspects of language learning, such as analytical ability of linguistic aspects. Yet, L2 children are perceived as better L2 learners in the long term, as they possess the ability to master the phonological system of the L2 and have stronger memorization skills (Ellis \& Shintani, 2014; Agulló, 2006). However, L2 adults have certain linguistic characteristics in which they proceed in L2 learning, which are often L2 children lack to. For instance, they can discuss with their teacher how a particular rule occurs? They also can inquire of word's meaning in different contexts.

Because of these strengths, teachers should double their efforts to offer children L2 learners supporting material during the $\mathrm{CP}$, such as having them listen to native speakers or read aloud to underpin and improve their pronunciation skills (Deng \& Zhu, 2016). As presented in the current paper, particular studies have asserted the importance of the $\mathrm{CP}$, during which children have the ability to master L2 acquisition (Moskovsky, 2001). Instructors may need to focus more on input (listening and reading) when teaching children L2 learners rather than output once the learners begin to absorb language implicitly. Post-pubertal learners, however, may need to be granted the chance by their teachers to activate the output exemplified by speaking and writing, for instance, placing students (by L2 teachers) in groups when doing speaking and writing tasks to feed each other linguistically (Shank, 2005).

Ultimately, the $\mathrm{CPH}$ could contribute to solving particular problematic issues of teaching an L2. For instance, L2 teachers can employ appropriate and effective approaches when teaching L2 children or adults such as those demonstrated in this paper. Teaching children in a more implicit way is especially beneficial, as they tend to absorb language subconsciously (Krashan, 1982). In contrast, adults need to be instructed explicitly with clear instructions and explanations of grammatical mistakes (Muñoz, 2006); in addition, both groups should be urged to be as extroverted as possible to demonstrate what they have learnt (Zhang, 2009). Therefore, the appropriate teaching style when teaching an L2 is crucial, and teachers should be aware of how they make their choices.

\section{References}

Agulló, G. L. (2006). Overcoming age-related differences. ELT Journal, 60(4), 365-373. https://doi.org/10.1093/elt/ccl027

Baker, W., Trofimovich, P., Flege, J. E., Mack, M., \& Halter, R. (2008). Child-adult differences in second-language phonological learning: The role of cross-language similarity. Language and Speech, 51(4), 317-342. https://doi.org/10.1177/0023830908099068 
Bernaus, M., Wilson, A., \& Gardner, R. C. (2009). Teachers' motivation, classroom strategy use, students' motivation and second language achievement. Porta Linguarum. Retrieved from http://hdl.handle.net/10481/31869

Bialystok, E., \& Hakuta, K. (1999). Confounded age: Linguistic and cognitive factors in age differences for second language acquisition. Second Language Acquisition and the Critical Period Hypothesis.

Bitchener, J., \& Knoch, U. (2010). Raising the linguistic accuracy level of advanced L2 writers with written corrective feedback. Journal of Second Language Writing, 19(4), 207-217. https://doi.org/10.1016/j.jslw.2010.10.002

Bitchener, J., Young, S., \& Cameron, D. (2005). The effect of different types of corrective feedback on ESL student writing. Journal of Second Language Writing, 14(3), 191-205. https://doi.org/10.1016/j.jslw.2005.08.001

Craats, I. (2001). The third person, first and second language acquisition compared. Applied Linguistics in Articles, 66, 23-39.

DeKeyser, R. M. (2005). What makes learning second-language grammar difficult? A review of issues. Language Learning, 55(S1), 1-25. https://doi.org/10.1111/j.0023-8333.2005.00294.x

Deng, F., \& Zhu, L. Q. (2016). An analysis of critical period hypothesis in English teaching. Sino-US English Teaching, 13(2), 116-122. https://doi.org/10.17265/1539-8072/2016.02.003

Ellis, A. W., \& Young, A. W. (2013). Human cognitive neuropsychology: A textbook with readings. Psychology Press. https://doi.org/10.4324/9780203727041

Ellis, R. (2009). Implicit and explicit learning, knowledge and instruction, implicit and explicit knowledge in second language learning, testing and teaching (pp.3-25). Bristol, UK: Multilingual Matters. https://doi.org/10.21832/9781847691767-003

Ellis, R., \& Shintani, N. (2014). Exploring language pedagogy through second language acquisition research. Oxen: Routledge. https://doi.org/10.4324/9780203796580

Flege, J. E. (1988). Factors affecting degree of perceived foreign accent in English sentences. The Journal of the Acoustical Society of America, 84(1), 70-79. https://doi.org/10.1121/1.396876

Gilkerson, J. (2006). Acquiring English particle verbs: Age and transfer effects in L2 acquisition. Inaugural Generative Approaches to Language Acquisition North America (GALANA). University of Hawai'i, Honolulu, USA.

Hurford, J. R. (1991). The evolution of the critical period for language acquisition. Cognition, 40(3), 159-201. https://doi.org/10.1016/0010-0277(91)90024-X

Johnson, J. S., \& Newport, E. L. (1989). Critical period effects in second language learning: The influence of maturational state on the acquisition of English as a second language. Cognitive Psychology, 21(1), 60-99. https://doi.org/10.1016/0010-0285(89)90003-0 


\section{Macrothink}

International Journal of Linguistics

ISSN 1948-5425

2020, Vol. 12, No. 6

Johnson, J. S., \& Newport, E. L. (1991). Critical period effects on universal properties of language: The status of subjacency in the acquisition of a second language. Cognition, 39(3), 215-258. https://doi.org/10.1016/0010-0277(91)90054-8

Krashen, S. D. (1982). Child-Adult Differences in Second Language Acquisition. Series on Issues in Second Language Research. Newbury House Publishers, Inc., Rowley, MA 01969. https://doi.org/10.2307/3586451

Krashen, S. D., Long, M. A., \& Scarcella, R. C. (1979). Age, rate and eventual attainment in second language acquisition. TESOL Quarterly, 13(4), 573-582.

Lai, E. R. (2011). Motivation: A literature review. Person Research’s Report.

Lamendella, J. T. (1977). General principles of neurofunctional organization and their manifestation in primary and nonprimary language acquisition 1. Language Learning, 27(1), 155-196. https://doi.org/10.1111/j.1467-1770.1977.tb00298.x

Lenneberg, E. (1967). Biological foundations of language. New York: Wiley. https://doi.org/10.1080/21548331.1967.11707799

Long, M. H. (1990). Maturational constraints on language development. Studies in Second Language Acquisition, 12(03), 251-285. https://doi.org/10.1017/S0272263100009165

Moskovsky, C. (2001). The critical period hypothesis revisited. Proceedings of the 2001 Conference of the Australian Linguistic Society.

Muñoz, C. (2006). Age and the rate of foreign language learning. Multilingual Matters. https://doi.org/10.21832/9781853598937

Muñoz, C. (2008). Symmetries and asymmetries of age effects in naturalistic and instructed L2 learning. Applied Linguistics, 29(4), 578-596. https://doi.org/10.1093/applin/amm056

Petchprasert, A. (2012). Feedback in second language teaching and learning. US-China Foreign Language, 10(4), 1112-1120.

Rocca, S. (2007). Child second language acquisition: A bi-directional study of English and Italian tense-aspect morphology. John Benjamins Publishing. https://doi.org/10.1075/sibil.35

Rod, E. (1997). Second language acquisition. Oxford: Oxford University Press.

Schunk, D. H. (1984). Sequential attributional feedback and children's achievement $\begin{array}{lllll}\text { behaviours. Journal of Educational Psychology, } & 7159 \text { (6), }\end{array}$ https://doi.org/10.1037/0022-0663.76.6.1159

Scovel, T. (2000). A critical review of the critical period research. Annual Review of Applied Linguistics, 20, 213-223. https://doi.org/10.1017/S0267190500200135

Shanks, D. R., Lamberts, K., \& Goldstone, R. L. (2005). Implicit learning. Handbook of Cognition, 202-220. https://doi.org/10.4135/9781848608177.n8 


\section{Macrothink}

International Journal of Linguistics

ISSN 1948-5425

2020, Vol. 12, No. 6

Sharp, A. (2009). Personality and second language learning. Asian Social Science, 4(11), 17. https://doi.org/10.5539/ass.v4n11p17

Singleton, D. (2001). Age and second language acquisition. Annual Review of Applied Linguistics, 21, 77-89. https://doi.org/10.1017/S0267190501000058

Singleton, D. (2005). The critical period hypothesis: A coat of many colours. International Review of Applied Linguistics in Language Teaching, 43(4), 269-285. https://doi.org/10.1515/iral.2005.43.4.269

Staci-Anne, A. L. I. (2013). Exploring motivational strategies for second language learners amongst first year Japanese students. The Journal of Liberal Arts, Nagoya University of Arts and Sciences, (9), 141-161.

Swain, M. (1995). Three functions of output in second language learning. Principle and practice in applied linguistics: Studies in honour of HG Widdowson, 125144.

Zhang, Y. (2009). The role of personality in second language acquisition. Asian Social Science, 4(5), 58. https://doi.org/10.5539/ass.v4n5p58

\section{Copyrights}

Copyright for this article is retained by the author(s), with first publication rights granted to the journal.

This is an open-access article distributed under the terms and conditions of the Creative Commons Attribution license (http://creativecommons.org/licenses/by/4.0/) 